\title{
Formação Continuada de Professores em Pensamento Computacional: Um Relato de Experiência do Programa Norte-rio-grandense de Pensamento Computacional
}

\author{
Jeanne S. B. Bulcão \\ Instituto Metrópole Digital \\ UFRN / Universidade Federal do Rio Grande do Norte \\ Natal - RN - Brasil \\ jeannebulcao1@gmail.com \\ Carlos Artur Guimarães \\ Instituto Metrópole Digital \\ UFRN / Universidade Federal do Rio Grande do Norte \\ Natal - RN - Brasil \\ arturguimaraes@gmail.com
}

\author{
Charles Madeira \\ Instituto Metrópole Digital \\ UFRN / Universidade Federal do Rio Grande do Norte \\ Natal - RN - Brasil \\ charles@imd.ufrn.br \\ Crisiany Alves \\ Instituto Metrópole Digital \\ UFRN / Universidade Federal do Rio Grande do Norte \\ Natal - RN - Brasil \\ crisianyalves@gmail.com
}

\begin{abstract}
RESUMO
A sociedade contemporânea há tempos tem experimentado mudanças e transformações provocadas pelos avanços científicos e tecnológicos que afetam e modificam o mercado de trabalho, as relações sociais, a cultura, a ciência e a educação. Entretanto, chama atenção o fato da Educação Básica brasileira ainda não estar alinhada a esta tendência mundial e ainda ensaiar experiências de integração das tecnologias digitais na rotina das escolas públicas. Isso se deve, em parte, à formação inicial dos professores que pouco contempla o uso pedagógico das tecnologias digitais para os processos de ensino e de aprendizagem. Além disso, também se torna cada vez mais necessário incentivar práticas educativas que estimulem habilidades relacionadas à capacidade de resolver problemas, lidar com frustrações e criar soluções como condições essenciais para que as pessoas possam se desenvolver integralmente e profissionalmente, permitindo o ingresso e a manutenção no mercado de trabalho. Neste sentido, uma direção que vem se popularizando nos últimos anos e tem incentivado o aparecimento de um grande número de iniciativas relacionadas ao uso das tecnologias digitais na educação é a do Pensamento Computacional. É nesta direção que se insere o presente artigo que tem como objetivo relatar a experiência de um curso de formação continuada em Pensamento Computacional do Programa Norte-riograndense de Pensamento Computacional (PENSA RN), realizado com professores do Ensino Fundamental dos anos finais. Esse curso uniu as metodologias da aprendizagem baseada em resolução de problemas, computação desplugada, jogos digitais e programação visual, a fim de estimular o desenvolvimento do Pensamento Computacional como um instrumento de aumento do poder cognitivo e operacional humano, integrando-o nas práticas

Fica permitido ao(s) autor(es) ou a terceiros a reprodução ou distribuição, em parte ou no todo, do material extraído dessa obra, de forma verbatim, adaptada ou remixada, bem como a criação ou produção a partir do conteúdo dessa obra, para fins não comerciais, desde que sejam atribuídos os devidos créditos à criação original, sob os termos da licença CC BY-NC 4.0.

EduComp'21, Abril 27-30, 2021, Jatai, Goiás, Brasil (On-line)

(C)2021 Copyright mantido pelo(s) autor(es). Direitos de publicação licenciados à Sociedade Brasileira de Computação (SBC).
\end{abstract}

pedagógicas dos professores. Como resultados da experiência, os professores adotaram novas estratégias no seu ambiente de trabalho, elaborando e aplicando práticas educativas integradas ao Pensamento Computacional em escolas públicas da rede de ensino.

\section{PALAVRAS-CHAVE}

Formação Continuada, Educação Básica, Pensamento Computacional, Metodologias Ativas

\section{Introdução}

Apesar de vivermos numa sociedade na qual os profissionais das mais diversas áreas passam grande parte do seu tempo utilizando computadores, a Educação Básica brasileira ainda caminha para efetivar práticas de integração das tecnologias digitais na rotina das escolas. Para que ocorra essa integração, é necessário repensar a formação inicial dos professores e proporcionar formações continuadas que contemplem o uso pedagógico das tecnologias digitais para os processos de ensino e aprendizagem [15]. A questão é que as novas formas de produção e disponibilização do conhecimento estão provocando profundas mudanças na maneira de ensinar e de aprender, criando um novo universo para o ecossistema da educação. Portanto, para acompanhar as mudanças e evoluções da sociedade, é necessário haver um enriquecimento escolar para dar espaço ao uso das tecnologias digitais e proporcionar a inovação e a melhoria dos processos de ensino e de aprendizagem, ensinando aos jovens alunos que as tecnologias digitais também servem para produzir conhecimento novo e novas tecnologias [16].

É neste contexto que se insere o Programa de Inovação Educação Conectada do Ministério da Educação [3], que tem como objetivo apoiar a universalização do acesso à internet de alta velocidade, formar professores e gestores e fomentar o uso dos recursos educacionais digitais na Educação Básica. Para além, a Base Nacional Comum Curricular (BNCC), que é um documento normativo das aprendizagens essenciais que todos os estudantes devem desenvolver ao longo das etapas e modalidades da Educação Básica, apresenta dez competências gerais a serem desenvolvidas 
desde a educação infantil até o ensino médio [3]. Dentre essas competências gerais, está a competência de cultura digital, que visa estimular práticas relacionadas à compreensão, utilização e criação de Tecnologias Digitais de Informação e Comunicação para o exercício da cidadania e para a resolução de problemas.

É nesse sentido que nos últimos anos tem emergido um volume significativo de iniciativas com vistas ao uso das metodologias ativas e das tecnologias digitais na educação, como é o caso do pensamento computacional [4] que é uma abordagem geral para resolução de problemas e conta com o desenvolvimento de um corpo de pesquisas mundialmente robusto [1][8][9]. O pensamento computacional ajuda a ensinar os indivíduos a pensar mais eficazmente pelo fato de formalizar a concepção de sistemas e trabalhar na compreensão do comportamento humano, se mostrando como habilidades bastante relevantes para as mais diversas profissões.

Portanto, é vital para o desenvolvimento do país que o Pensamento Computacional seja fomentado nas escolas da Educação Básica, promovendo a alfabetização tecnológica dos jovens a partir do desenvolvimento de práticas que permitam o acesso, produção e reflexão sobre as tecnologias digitais, conforme indica o Currículo de Referência em Tecnologia e Computação do Centro de Inovação para a Educação Brasileira (CIEB) [2].

Esse currículo de referência tem como objetivo oferecer diretrizes e orientações para apoiar as redes de ensino e escolas a incluir os temas tecnologia e computação em suas propostas curriculares. Para tanto, as habilidades propostas no documento estão diretamente associadas às competências gerais e habilidades da BNCC e apresentam sugestões de recursos e materiais que podem ser utilizados pelos professores para aplicar o pensamento computacional em suas ações pedagógicas, além de contribuir para disseminação de práticas pedagógicas integradas ao pensamento computacional nas escolas públicas. Tal integração entre o ensino de Pensamento Computacional e os conteúdos formativos através das tecnologias digitais pode contribuir para a melhoria dos indicadores educacionais e atualização da formação dos alunos.

Portanto, torna-se necessário e urgente a oferta de cursos de formação continuada que ofereçam subsídios para o desenvolvimento de novos conhecimentos por parte dos professores e dos estudantes, em um contexto de aprendizagem mão na massa na qual possibilite o exercício e a aplicação dos novos conhecimentos na prática pedagógica.

É nesse contexto que este trabalho se insere relatando uma experiência concreta de formação continuada de professores voltada ao desenvolvimento do pensamento computacional. Essa formação se caracteriza como uma iniciativa do Programa Norteriograndense de Pensamento Computacional (PENSA RN), que visa criar uma cultura de integração do pensamento computacional nas dinâmicas das ações pedagógicas das escolas do Ensino Básico. Isso envolve desde uma mudança nas práticas educativas dos professores até a criação de clubes de programação nas escolas.

\section{Trabalhos Relacionados}

Iniciativas alinhadas aos programas ou projetos educacionais municipais e estaduais para integração do Pensamento Computacional nas práticas docentes, visando a formação de professores neste tema, ainda são incipientes no Brasil. Isto ocorre na contramão do número de pesquisas sobre a temática, que tem crescido vertiginosamente desde a publicação do artigo de Jeannette Wing em 2006 [4].

São muitos os estudos que relatam experiências formativas em Pensamento Computacional com professores e alunos e que apontam resultados significativos no desenvolvimento de habilidades e competências para resolução de problemas e de aumento do poder cognitivo, da capacidade criativa e da resiliência.

Dentre essas pesquisas, [11][12][6] apresentam propostas semelhantes entre si, no sentido de disseminar e integrar o Pensamento Computacional nas práticas educativas dos professores. Os dois primeiros trabalhos ocorrem por iniciativas de instituições de ensino superior, sendo vinculado à disciplina de estágio docente ou curso de extensão universitária. O terceiro trabalho apresenta uma proposta mais semelhante à formação ora descrita neste artigo, visto que ele descreve uma proposta presencial, sendo uma iniciativa mobilizada em parceria entre uma universidade e uma secretaria de educação do estado. As duas primeiras iniciativas apresentam uma organização modular, com o ensino de linguagem de programação visual para criação e desenvolvimento de jogos digitais. Embora semelhante às demais iniciativas no aspecto da organização, a terceira iniciativa inclui práticas plugadas e desplugadas utilizando, fortemente, a análise de micromundos, como aquelas vistas em [7] para desenvolvimento de ideias e reflexões acerca do que é o Pensamento Computacional e como integrá-lo na prática de ensino.

Para além desses trabalhos, o Programa de Inovação Educação Conectada, por meio da plataforma virtual de aprendizagem AVAMEC do Ministério da Educação - MEC, também tem fornecido formações continuadas no tema do Pensamento Computacional. No modelo do AVAMEC, diferentemente dos demais cursos de formação, não são apresentados os objetivos, os saberes e as competências relacionadas ao Pensamento Computacional a serem desenvolvidas pelos professores. $\mathrm{O}$ curso possui estratégias semelhantes a uma das metodologias utilizadas no âmbito do Projeto Programaê, apresentado por [6] em relação a análise de situações-problemas e análises de micromundo. Nessas estratégias, os professores precisam oferecer uma resolução para a situação-problema apresentada no módulo ou oficina.

Essas iniciativas de formação continuada possuem um design de aprendizagem que se volta a um modelo de formação centrada apenas na aprendizagem de novos conhecimentos e saberes sobre $o$ Pensamento Computacional. Embora relevantes, essas formações deixam secundarizados aspectos sobre o desenvolvimento profissional em que a aprendizagem da docência perpassa por uma ação profunda e sistematizada, orientada para a mudança do professor como profissional, incluindo não apenas o saber e o conhecimento, mas também o saber fazer, o ser, e o saber pensar [13].

A formação continuada dessa maneira precisa ser mais que instrução ou aprendizagem de conhecimento, visto que inclui interesses, intenções, motivações, capacidades, condutas, atitudes, valores, dentre outros elementos, que levam ao desenvolvimento profissional dos professores.

Apesar dessas formações possuírem semelhanças com a formação continuada do PENSA RN em relação a organização em módulos, aprendizagem de vários conhecimentos e tecnologias, seleção dos materiais e na organização dos objetivos, elas também se diferenciam na aplicação de algumas estratégias que visam o desenvolvimento profissional dos professores aos processos de ensino e aprendizagem em Pensamento Computacional.

Dessa forma, as experiências evidenciadas anteriormente foram analisadas e contribuíram para a organização e sistematização da proposta do Curso de Formação Continuada de Professores do Programa Norte-rio-grandense de Pensamento Computacional descrita na próxima seção. 
Formação Continuada de Professores em Pensamento Computacional: Um Relato de Experiência do PENSA RN

\section{Proposta do Curso de Formação Continuada de Pensamento Computacional do PENSA RN}

O presente curso de formação continuada de professores em Pensamento Computacional é parte do Programa Norte-riograndense de Pensamento Computacional (https://pensarn.imd.ufrn.br/), que é um programa estadual de fomento ao desenvolvimento de habilidades do pensamento computacional, visando criar uma nova cultura de inovação em educação na dinâmica das ações pedagógicas das Instituições de Ensino Básico. O Programa envolve três atividades principais:

- Cursos de formação continuada de professores;

- Clube de programação para alunos dos anos finais do ensino fundamental das escolas públicas;

- Sistema de avaliação diagnóstica das habilidades em pensamento computacional.

Além de conhecimentos, habilidades e competências docentes, a proposta de formação continuada de professores foi planejada e operacionalizada por uma equipe multidisciplinar, composta por discentes e docentes de cursos de pós-graduação em nível de mestrado e doutorado com formações iniciais nas áreas da ciência da computação, psicologia e pedagogia. A proposta foi desenhada visando:

- Mobilizar a elaboração de trilhas de aprendizagem para serem aplicadas com os alunos;

- Formular situações de aprendizagem com foco na exploração e utilização de materiais e documentos que fazem parte do desenvolvimento profissional dos docentes, como é o caso da BNCC e do Currículo do CIEB;

- Elaborar materiais desplugados para serem utilizados pelos professores com os alunos.

Os módulos tiveram uma organização didático-pedagógico em que os objetivos (geral e específicos) de aprendizagem, metodologia, recursos didáticos e referências foram sistematizados em um modelo de trilha previamente definida pela equipe multidisciplinar. No modelo da trilha, os formadores tinham que definir, com base nos objetivos do curso, os objetivos específicos, as estratégias metodológicas, os recursos didáticos e as ferramentas que melhor atendessem aos objetivos de aprendizagem propostos e aos critérios de avaliação dos professores.

Conforme aponta [13], a formação continuada deve mobilizar saberes docentes que provoquem novas aprendizagens capazes de tributar ao desenvolvimento profissional dos educadores, em sua forma de pensar e agir no exercício da sua profissão. Nesse sentido, a formação continuada do Programa Norte-rio-grandense de Pensamento Computacional foi planejada para alcançar objetivos relacionados à aprendizagem da profissão, a formação e o desenvolvimento profissional do professor, com vistas a:

- Promover a formação de profissionais que conduzam a aplicação das tecnologias educacionais de Pensamento Computacional, visando a solução de problemas relacionados ao ensino e à aprendizagem, de forma a atender demandas de naturezas diversas das instituições de ensino;
EduComp'21, Abril 27-30, 2021, Jataí, Goiás, Brasil (On-line)

- Possibilitar a continuidade formativa de docentes atuantes no Ensino Fundamental;

- Construir colaborativamente conhecimentos que possibilitem o desenvolvimento de valores, competências, habilidades e capacidades que promovam um exercício profissional crítico-reflexivo através das tecnologias educacionais;

- Estabelecer relação entre aspectos teóricos e práticos sobre o uso pedagógico das tecnologias digitais;

- Propiciar experiências que contribuam para a inovação das práticas pedagógicas.

Os módulos foram organizados de modo a estimular a mudança de mentalidade dos professores sobre as possibilidades de implementação de práticas pedagógicas integrando o Pensamento Computacional, mesmo em contextos de aprendizagem em que haja extrema escassez tecnológica nos espaços escolares.

Destaca-se que a proposta de formação continuada, descrita e narrada neste artigo, foi embasada em trabalhos anteriores que indicaram estratégias, recursos tecnológicos e materiais didáticos, assim como organização e estrutura dos módulos. Dentre esses, estão os trabalhos de [5][10][14], que contribuíram fortemente na organização dos conteúdos dos módulos e na formulação das trilhas de aprendizagem, além daqueles demais estudos citados na seção de trabalhos relacionados.

A formação continuada foi estruturada inicialmente em dez módulos, totalizando 60 horas de carga horária, contemplando aspectos relacionados à visão sobre as mudanças que a sociedade atual tem passado, o conceito e os pilares do pensamento computacional, além de práticas plugadas e desplugadas. $\mathrm{O}$ curso foi organizado conforme o Quadro 1.

O módulo um teve como objetivo discutir com os professores as mudanças observadas e sentidas na sociedade atual, os desafios que os estudantes deverão estar preparados para resolver em razão das transformações e das mudanças provocadas pelos avanços científicos e tecnológicos. Neste módulo ainda foi estimulado a mudança de mentalidade dos professores, conhecendo e vivenciando as dimensões do Programa de Inovação Educação Conectada: visão, competências e formação, recursos educacionais e infraestrutura, por meio da reflexão através da matriz SWOT, seguido por elaboração e criação de um plano de ação.

O módulo objetivou apresentar e explorar o Currículo de Referência em Tecnologia e Computação do CIEB, relacionando-o com o currículo da rede de ensino e a BNCC. Em relação ao currículo do CIEB, os professores foram estimulados a refletir, explorar e identificar os elementos que constituem este documento, além de conhecerem os diversos materiais relacionados às habilidades da BNCC que poderiam ser utilizados pelos professores em suas práticas de ensino.

Os módulos três e quatro tiveram o objetivo incentivar a aprendizagem de conceitos relacionados ao pensamento computacional e às olimpíadas de conhecimento. No módulo três, o objetivo consistiu em apresentar e trabalhar com os professores a partir da exploração do currículo do CIEB, as dimensões do pensamento computacional (decomposição, abstração, reconhecimento de padrões e algoritmos) para a sua integração na área de conhecimento dos professores. No módulo quatro, o objetivo consistiu em apresentar as olimpíadas de conhecimento, especialmente a Olimpíada Brasileira de Informática, para 
promover a compreensão dos professores sobre a importância destas olimpíadas na formação dos estudantes.

\begin{tabular}{|c|c|c|}
\hline Módulo 01 & $\begin{array}{l}\text { Programa de Inovação Educação } \\
\text { Conectada }\end{array}$ & $6 \mathrm{~h}$ \\
\hline Módulo 02 & $\begin{array}{l}\text { Currículo de Referência em Tecnologia e } \\
\text { Computação }\end{array}$ & $6 \mathrm{~h}$ \\
\hline Módulo 03 & Pensamento Computacional & $6 \mathrm{~h}$ \\
\hline Módulo 04 & Olimpíadas de Conhecimento & $6 \mathrm{~h}$ \\
\hline Módulo 05 & PENSA RN & $6 \mathrm{~h}$ \\
\hline Módulo 06 & $\begin{array}{l}\text { Prática do Pensamento Computacional } \\
\text { com Computação Desplugada }\end{array}$ & $6 \mathrm{~h}$ \\
\hline Módulo 07 & $\begin{array}{l}\text { Prática do Pensamento Computacional } \\
\text { com a Hora do Código }\end{array}$ & $6 \mathrm{~h}$ \\
\hline Módulo 08 & $\begin{array}{l}\text { Prática do Pensamento Computacional } \\
\text { com Scratch }\end{array}$ & $6 \mathrm{~h}$ \\
\hline Módulo 09 & $\begin{array}{l}\text { Prática de Observação da Execução de } \\
\text { Clube de programação }\end{array}$ & $6 \mathrm{~h}$ \\
\hline Módulo 10 & $\begin{array}{l}\text { Prática de Avaliação Diagnóstica das } \\
\text { Habilidades do Pensamento } \\
\text { Computacional }\end{array}$ & $6 \mathrm{~h}$ \\
\hline
\end{tabular}

Quadro 1: Módulos e carga horária do curso de formação continuada

No módulo cinco, foi apresentado o programa do qual o curso de formação continuada faz parte. Este módulo foi inserido neste momento em razão da organização do curso entender que seria mais fácil conseguir adesão dos professores na implementação da proposta central do programa assim que estes tivessem sido sensibilizados quanto às mudanças pelas quais passam a sociedade contemporânea, assim como conhecessem o conceito de pensamento computacional e tivessem a oportunidade de integrá-lo na sua prática de ensino. Dessa forma, o módulo apresentou em detalhes o programa em questão de Pensamento Computacional, sua importância e principais ações junto aos professores e estudantes da educação básica da rede estadual de educação.

Nos módulos seis, sete e oito os professores tiveram a oportunidade de experimentar a construção de conceitos e saberes sobre computação desplugada e computação plugada mediante atividades práticas utilizando gamificação, jogos, Scratch e os desafios da Hora do Código. Estes módulos tiveram como objetivo principal apresentar recursos educacionais digitais que os professores poderiam utilizar para desenvolver práticas de ensino integradas ao pensamento computacional.
No módulo nove, os professores frequentaram o clube de programação do Programa Norte-rio-grandense de Pensamento Computacional com o intuito de adquirir uma primeira experiência com a aplicação de atividades plugadas juntamente aos alunos dos anos finais do Ensino Fundamental. Enfim, no módulo dez estava prevista a aplicação de um modelo de avaliação diagnóstica para as habilidades do pensamento computacional. Porém, por questões de organização e adaptações em razão de mudanças de agendas, feriados e outros desafios, esse último módulo não pôde ser realizado como o previsto. Portanto, os professores foram incentivados a dar continuidade com a participação nos encontros do clube de programação.

Quanto à metodologia do curso, durante os módulos foram utilizadas estratégias baseadas na resolução de problemas, computação desplugada, jogos digitais e programação visual a fim de estimular nos professores o desenvolvimento do pensamento computacional de uma forma prática e colaborativa.

Em relação a avaliação dos professores, esta ocorreu de forma processual e formativa utilizando-se de diversos materiais e produções dos professores durante o curso de formação continuada como, por exemplo, trilhas de aprendizagem, participação ativa nos módulos, criação de artefatos de jogos ou animações nos ambientes de programação visual e observação subjetiva dos formadores ministrantes do curso.

Em relação à avaliação da qualidade do curso, foram aplicados questionários durante e após os módulos, assim como no final do curso. Para coleta dos dados de avaliação, foram utilizados dois tipos de formulários on-line estruturados para produzir um perfil do formador, perfil docente dos participantes e avaliação do curso.

\section{Aplicação da Proposta de Formação Continuada do PENSA RN}

O curso de formação continuada do PENSA RN ocorreu no período de setembro a novembro de 2019 , contando com 40 professores do ensino fundamental dos anos finais de uma rede estadual de ensino.

No módulo um, em um primeiro momento foi utilizada a dinâmica do World Café, um processo colaborativo que visa trabalhar a diversidade e complexidade no grupo, fazendo emergir a inteligência coletiva [17]. Os participantes se organizaram em grupos e refletiram sobre as forças, oportunidades, fraquezas e ameaças (Matriz SWOT) acerca das dimensões visão, competências e formação, recursos educacionais e infraestrutura do Programa de Inovação Educação Conectada (PIEC).

No segundo momento houve a utilização da ferramenta para planejamento estratégico $5 \mathrm{~W} 2 \mathrm{H}$, com vistas a estimular nos professores uma nova perspectiva acerca da realidade de suas escolas. Organizados em grupos, os professores se reportaram às reflexões levantadas no world café para construir e propor soluções frente às dimensões PIEC, desenvolvendo práticas inovadoras que fossem possíveis de ser aplicadas em suas respectivas escolas. Inicialmente, os professores tiveram dúvidas sobre como poderiam propor soluções para os problemas enfrentados em suas respectivas escolas. Eles alegaram que a grande maioria dos problemas enfrentados estava relacionado com a infraestrutura, devido aos recursos escassos disponíveis nas escolas. Para a surpresa de todos, embora fossem de escolas distintas, muitos dos problemas eram semelhantes, o que possibilitou aos professores a concepção de soluções que poderiam ser aplicadas em qualquer uma das escolas 
Formação Continuada de Professores em Pensamento Computacional: Um Relato de Experiência do PENSA RN

representadas. Na Figura 1 é possível observar dois grupos de professores apresentando seus projetos.

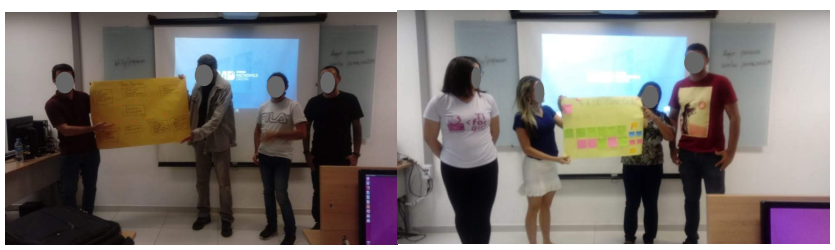

Figura 1: Professores apresentando os projetos desenvolvidos no módulo um utilizando a metodologia 5W2H e World Café.

Destaca-se, no entanto, que quase todos os grupos de professores tiveram foco em soluções que não dependiam exatamente deles, como por exemplo a compra de equipamentos de informática, a melhoria na administração e gestão dos recursos da escola, a oferta de formações continuadas na própria escola, a promoção de eventos para arrecadação de fundos etc. Foram poucos os professores que apontaram para a necessidade de uma nova ecologia na escola, em que eles pudessem ser protagonistas juntamente com os estudantes por meio de atividades e ações colaborativas e inovadoras, trabalhando com metodologias ativas e com os recursos disponíveis dentro e fora da escola, independentemente da utilização de tecnologias digitais.

Essa observação foi extremamente valiosa para que nos módulos seguintes fossem reforçadas as situações de aprendizagem colaborativa, estimulando os professores para refletirem sobre o que, como, para quê, e, porquê utilizar as tecnologias disponíveis na escola para a integração do Pensamento Computacional em sua prática de ensino.

No módulo dois, os professores tiveram que selecionar e analisar um plano de aula do portal do Programaê (http://programae.org.br/) para compreender como os planos de aulas foram criados e como poderiam ser aplicados em suas realidades de ensino. A proposta do módulo era apresentar aos professores os materiais e os recursos disponíveis que poderiam ser aplicados com seus alunos. Após essa exploração dos materiais, os professores analisaram um plano de aula voltado ao ensino da educação física para os estudantes do $7^{\circ}$ ano do Ensino Fundamental.

Neste módulo ficou evidente que muitos professores não apresentavam muita familiaridade com os recursos tecnológicos digitais. Além dessa constatação ser um dado bastante significativo, que pode influenciar a permanência ou não dos professores no curso, este dado também aponta para os desafios que o Brasil ainda terá que avançar para integrar as tecnologias digitais de forma inovadora, como recursos de criação, colaboração e transformação social.

Além das dificuldades em localizar o portal do Programaê e navegar nele, os professores também tiveram dificuldades em compreender o objetivo da atividade proposta, demonstrando assim a necessidade de ter que trabalhar o básico do uso dos sistemas computacionais.

No módulo três, o objetivo era contribuir com a formação dos professores no sentido de estimular a compreensão sobre o que é o pensamento computacional, sua relação com a educação e como poderia ser integrado à prática de ensino das diversas áreas de conhecimento. Para alcançar esses objetivos, no módulo foram utilizadas as seguintes estratégias didáticas nos encontros: apresentação dialogada de slides sobre a contextualização do módulo e teóricos do pensamento computacional; discussão colaborativa sobre o tema do encontro de formação; e o direcionamento sobre a trilha integrando pensamento computacional à prática de ensino dos professores.

Para além, foram propostos momentos de vivências colaborativas, envolvendo atividades utilizando programação plugada e desplugada, por meio de atividades como cupcakes e estacionamento do site (https://www.computacional.com.br/) e os jogos Compute-it (http://compute-it.toxicode.fr/) e Lightbot (https://ightbot.com/) que possibilitaram trabalhar os pilares do pensamento computacional.

Quanto à experimentação da computação plugada, esta ocorreu de forma individual no laboratório de informática e foi direcionada com base em diversas questões, tais como: "Você consegue aplicar as dimensões do pensamento computacional?"; "Em qual (is) situação (ões) você aplicou a abstração, a decomposição, o reconhecimento de padrão e a elaboração de algoritmo no jogo?".

Em relação à vivência utilizando a computação desplugada, os professores foram agrupados em quatro grupos compostos por cinco a seis componentes. As atividades desplugadas foram organizadas em quatro estações em que os professores passavam de atividade em atividade, trocando-as em intervalos de 30 a 40 minutos. A Figura 2 apresenta alguns registros da aplicação das dinâmicas com os professores.

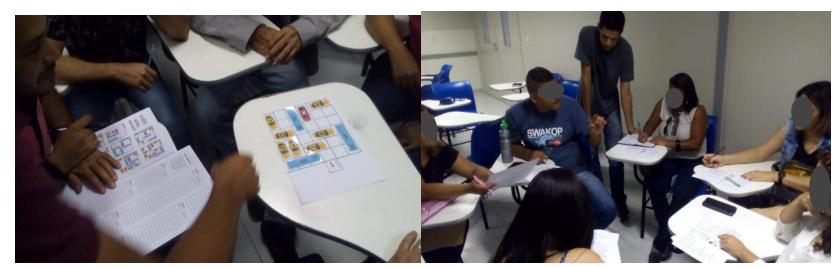

Figura 2: Professores resolvendo atividades de computação desplugada

Quanto à avaliação dos professores, para além dela ocorrer de forma processual e formativa, também foi solicitado aos professores a elaboração e aplicação de uma prática pedagógica integrada ao Pensamento Computacional. Em relação a avaliação do módulo também foi realizada aplicação de formulário on-line para validar as metodologias, estratégias, recursos utilizados e a linguagem adotada pelos formadores durante os encontros.

A avaliação dos encontros formativos não foi obrigatória. Portanto, apenas 16 professores avaliaram o módulo. Para os professores, o tempo dedicado ao módulo, a metodologia empregada, os recursos utilizados, o domínio apresentado pelos formadores e a clareza na comunicação se mostraram de acordo com as suas expectativas, ficando com variações entre quatro e cinco pontos, considerando uma escala de um a cinco.

Em relação à produção dos planos de aula integrando o Pensamento Computacional, todos os professores produziram trilhas de aprendizagem, em alguns casos de forma colaborativa. As trilhas foram aplicadas posteriormente com os estudantes de várias escolas da rede estadual de ensino. Destaca-se que essas propostas de ação pedagógica serão disponibilizadas para consulta no portal do PENSA RN. 
No módulo quatro, os formadores apresentaram os benefícios para os alunos, professores e escolas em participar das olimpíadas brasileiras de conhecimento, inclusive para ajudar a identificar possíveis casos de estudantes com altas habilidades. Após a aplicação inicial dos conceitos durante a apresentação dialogada sobre os temas do encontro, os professores foram organizados em grupos de seis componentes. Em seguida, foram sorteadas as olimpíadas para que cada grupo pudesse se aprofundar e trazer informações para o grande grupo. Os professores deveriam elaborar uma apresentação sobre o tema do encontro e, depois, apresentar para a turma os seus achados.

Por meio dos slides criados pelos professores é possível perceber que estes conseguiram entender como esses eventos estão organizados, quais recursos são necessários e utilizados nas olimpíadas e, principalmente, sobre a importância desses eventos educacionais para descobrir novos talentos.

No módulo cinco ocorreu a apresentação do Programa Norterio-grandense de Pensamento Computacional, indicando sua importância, suas principais ações e explicação de como a avaliação diagnóstica está sendo construída. O módulo ocorreu de forma teórica, utilizando-se basicamente de apresentação dialogada sobre o tema, não havendo nenhuma produção concreta para ser elaborada pelos professores. Entretanto, esta ação foi importante para que os professores tivessem clareza sobre a dimensão do trabalho proposto, visando colaborar para a construção de um ecossistema de inovação e mudanças em suas práticas docentes, impactando assim na vida dos estudantes envolvidos nos clubes de programação em suas escolas.

No módulo seis, de Pensamento Computacional com computação desplugada, o objetivo consistiu em estimular vivências práticas dos professores na aplicação de recursos utilizando Pensamento Computacional mesmo em situações de extrema escassez tecnológica digital. No módulo, foram utilizadas as seguintes estratégias: apresentação dialogada sobre o tema, dinâmica gamificada e aplicação de um jogo da "caça pensamento computacional" (https://www.encurtador.com.br/oquDZ), conforme apresentado na Figura 3.

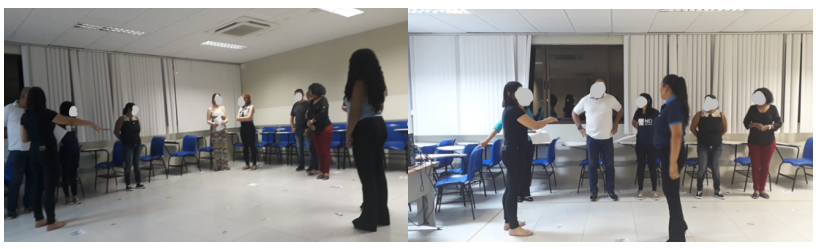

Figura 3: Aplicação do jogo "caça pensamento computacional", envolvendo conhecimento da matemática financeira.

Neste módulo não foi solicitado aos professores nenhum planejamento com Pensamento Computacional desplugado. Entretanto, após este módulo, muitos professores compartilharam registros de aplicações de atividades de computação desplugada em suas escolas semelhantes às apresentadas neste módulo e no módulo de Pensamento Computacional, conforme pode ser observado na Figura 4. Essa disposição em aplicar o Pensamento Computacional sem solicitação explícita dos formadores sugere que a formação serviu para incentivá-los, mostrando-os como desenvolver práticas educativas integradas ao Pensamento Computacional.

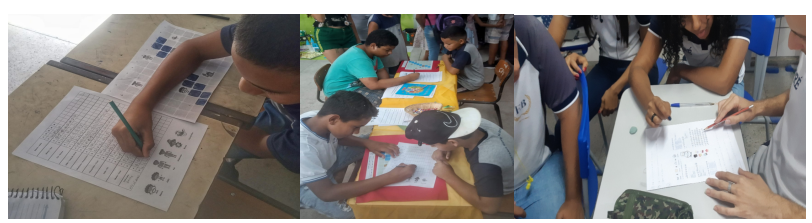

Figura 4: Atividade de computação desplugada sendo realizada por alunos de escolas públicas da rede estadual de ensino.

Nos módulos sete e oito aos professores foram apresentados os recursos para desenvolvimento e aplicação de propostas utilizando a criação de narrativas e animações. Nestes módulos, os professores tiveram a oportunidade de navegar nas plataformas da Hora do Código e do Scratch, exercitando a programação, observando os jogos existentes e planejando um jogo para ser desenvolvido posteriormente. A Figura 5 apresenta registros dos encontros.

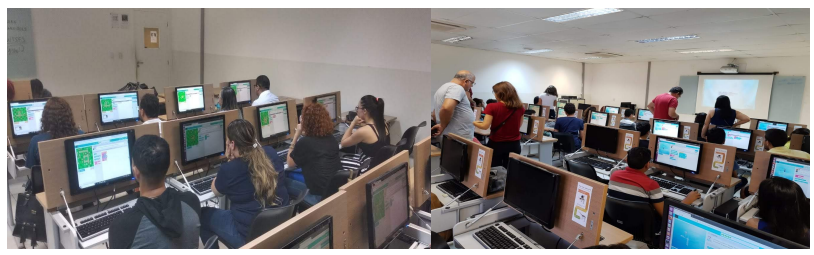

Figura 5: Práticas utilizando as plataformas da Hora do Código e do Scratch no laboratório de Informática.

Assim como no módulo de computação desplugada, os formadores envolvidos não solicitaram nenhuma atividade de planejamento e aplicação de propostas envolvendo o novo conhecimento adquirido pelos professores. Todavia, mesmo sem ter sido uma solicitação do módulo, os professores não deixaram de aplicar a computação plugada com os alunos. A Figura 6 apresenta evidências da aplicação desse novo conhecimento na prática educativa dos docentes nas escolas.

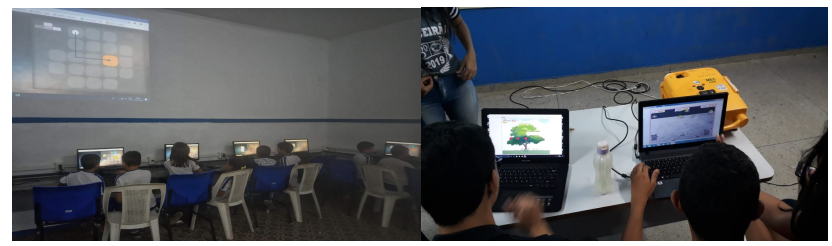

Figura 6: Práticas utilizando as plataformas da Hora do Código e do Scratch com os estudantes da rede estadual de ensino.

Nos módulos nove e dez os professores foram convidados a participar das intervenções do clube de programação do Programa Norte-riograndense de Pensamento Computacional, que estava sendo realizado no mesmo período com 120 alunos dos anos finais do Ensino Fundamental das escolas públicas. Os professores experienciaram a aplicação de diversas atividades de programação com várias ferramentas, compreendendo assim como um clube funciona e qual é o trabalho de mediação que precisa ser efetuado juntamente com os alunos. Um dos interesses principais desta participação dos professores no clube foi incentivá-los a criar clubes de programação nos seus próprios ambientes de trabalho a fim de dar a oportunidade para os alunos das respectivas escolas.

Em relação aos resultados gerais do curso, 22 professores chegaram a concluir a formação continuada. Dentre aqueles que finalizaram, 18 responderam ao formulário de avaliação do curso. 
Formação Continuada de Professores em Pensamento Computacional: Um Relato de Experiência do PENSA RN

Dentre aqueles que responderam ao formulário, 16 afirmaram que aplicaram o pensamento computacional com seus alunos nas escolas. No que se refere aos professores que desenvolveram práticas educativas envolvendo o pensamento computacional em suas práticas de ensino, $15 \%$ indicaram que fizeram uso de atividades desplugadas e 6\% afirmaram utilizar atividades gamificadas. Na Figura 7 é possível observar a distribuição das estratégias mais aplicadas pelos professores.

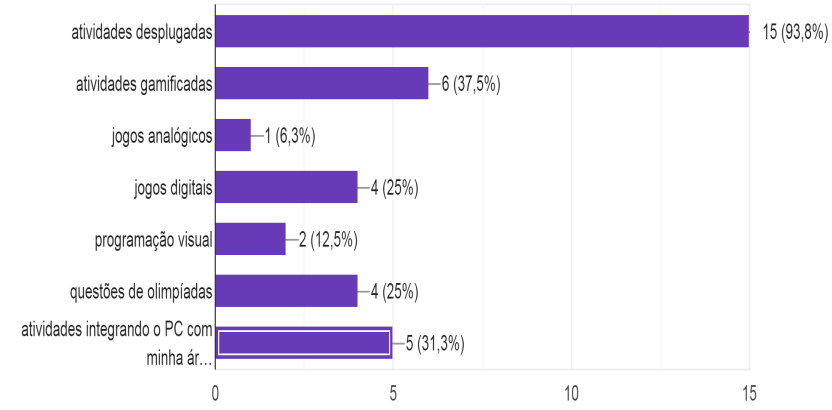

Figura 7: Gráfico indicando as estratégias utilizadas pelos professores em suas ações pedagógicas integrando pensamento computacional.

Apenas seis professores fizeram uso de computação plugada em suas escolas, reforçando a importância da computação desplugada como uma estratégia fundamental para disseminação do Pensamento Computacional, sobretudo naquelas escolas que contam com pouca infraestrutura tecnológica.

A Figura 7 também indica que ainda há muitos desafios a serem superados para que o ensino plugado ocorra, seja com a criação de narrativas e histórias, seja com a construção de animações digitais.

A escolha da abordagem desplugada e das estratégias gamificadas se deve provavelmente às condições de infraestrutura tecnológica digital disponíveis nas escolas dos professores. Entretanto, também pode revelar uma possível incompreensão dos docentes sobre a utilização das tecnologias digitais. A visão instrucionista ainda é muito presente na educação com o uso das tecnologias digitais, na qual a relação computador-estudante é de um-para-um, em que este ensina aquele.

Todavia, embora a abordagem instrucionista tenha se ofuscado por uma perspectiva de ensino construcionista, ainda há professores que acreditam e defendem que apenas será possível trabalhar com computação plugada nas escolas quando todos tiverem conectados a um computador, esquecendo-se muitas vezes do uso dos smartphones dos estudantes e do ensino híbrido.

É possível que o contexto das escolas públicas da rede, no que se refere à infraestrutura, seja um fator predominante para a adoção da computação desplugada em detrimento da plugada. Mas há também, por parte dos professores, pouca adesão a atividades pedagógicas apoiadas por abordagens híbridas, em que se possa realizar atividades dentro e fora da sala de aula utilizando os celulares dos estudantes e os computadores disponíveis na escola.

No que se refere à avaliação do curso realizada pelos professores, no Quadro 2 é possível observar as questões elaboradas e inseridas no formulário de avaliação, bem como o resultado da aplicação.
A partir da análise subjetiva da avaliação é possível identificar que o curso atendeu às expectativas dos professores quanto aos aspectos relacionados à qualificação técnica dos formadores, a qualidade dos materiais e recursos empregados, metodologias adotadas e as atividades envolvendo os participantes. Isto indica que estes elementos do design de aprendizagem do curso mostraram-se válidos e esses recursos e materiais podem ser reutilizados posteriormente novamente.

Em relação aos aspectos em que os professores consideraram pontos a serem melhorados fica claro que o modelo presencial do curso não atendeu em plenitude as demandas dos professores, visto que muitos participantes relataram que o modelo adotado era cansativo. Segundo os professores, o cansaço era fruto de um dia inteiro de trabalho em mais de uma escola. Ademais, os professores passavam o dia inteiro ministrando aulas e ainda tinham que se deslocar duas vezes por semana até o curso, que tinha duração de três horas de aulas-relógio.

Esse modelo de ensino, em que a presença física era necessária para validação do curso e desenvolvimento das atividades planejadas, além de ser visto pelos professores como algo negativo, pode ter sido também uma das causas de evasão no curso. Outro aspecto bastante significativo que também influenciou na permanência de alguns professores no curso foi o fato deles terem pouca proficiência tecnológica, desistindo assim do curso tão logo começaram as atividades plugadas no laboratório de informática.

Quanto às melhorias do curso, os professores indicaram basicamente uma necessidade de aumento da carga horária de atividades práticas, principalmente envolvendo computação desplugada e exercícios das olimpíadas de informática; atividades inclusivas para estudantes; adoção do modelo semipresencial; além de elaboração de materiais de apoio.

\begin{tabular}{|l|l|}
\hline O que foi bom? & $\begin{array}{l}\text { A possibilidade de conhecer mecanismos } \\
\text { para melhorar a prática educativa e } \\
\text { conhecer o pensamento computacional; a } \\
\text { didática e os recursos utilizados no curso } \\
\text { e a interação com outros colegas; } \\
\text { qualidade técnica dos formadores; } \\
\text { aprender a usar novas ferramentas } \\
\text { digitais; as vivências; a realização de } \\
\text { atividades com ênfase nas competências } \\
\text { e habilidades da BNCC; curso presencial; } \\
\text { aplicabilidade do tema no contexto } \\
\text { escolar. }\end{array}$ \\
\hline O que não foi bom? & $\begin{array}{l}\text { Tempo pouco; cortes na energia; } \\
\text { a carga horária dos encontros semanais } \\
\text { cansativa; o horário de término da aula e } \\
\text { deslocamento dos professores para suas } \\
\text { casas; o curso ter sido todo presencial; há } \\
\text { a necessidade de didática e objetividade } \\
\text { na apresentação das atividades; o módulo } \\
\text { das olimpíadas foi muito cansativo; a } \\
\text { distância e o cansaço; os encontros aos } \\
\text { sábados no clube de programação. }\end{array}$ \\
\hline
\end{tabular}




\begin{tabular}{|l|l|}
\hline & $\begin{array}{l}\text { Ampliação da carga horária; mais } \\
\text { atividades práticas; aumentar o tempo de } \\
\text { alguns módulos como o de olimpíadas e } \\
\text { computação desplugada; curso se tornar } \\
\text { Quais melhorias } \\
\text { você sugere para o } \\
\text { curso? }\end{array}$ \\
acessibilidade no desenvolvimento das \\
atividades; maior duração com mais \\
momentos de construção de atividades e \\
aplicação do pensamento computacional \\
em sala; ser semipresencial; continuidade \\
do curso; elaboração de um material \\
teórico para estudo; disponibilizar os \\
materiais em um AVA; aumento da carga \\
horária; atividade a distância; \\
aprendizagem baseada em projetos.
\end{tabular}

Quadro 2: Avaliação subjetiva dos professores sobre o curso de formação continuada.

Os resultados obtidos na formação continuada de professores do Programa Norte-rio-grandense de Pensamento Computacional parecem estar caminhando adequadamente, visto que as experiências desenvolvidas pelos professores, no ambiente do curso, demonstraram que apenas dois professores não se motivaram a aplicar o Pensamento Computacional em suas turmas. É provável que na próxima edição, deverá seguir para um modelo híbrido ou $100 \%$ online, o que demandará uma fundamentação teórica voltada para o ensino EAD.

\section{Considerações Finais}

O objetivo deste artigo foi apresentar, descrever e discutir a proposta inicial da formação continuada de professores em Pensamento Computacional do PENSA RN aplicada com educadores da Educação Básica.

Durante os módulos foi possível observar dificuldades dos professores no uso das TDIC, revelando a necessidade de se repensar o processo de validação do curso ou de criação de estratégias para minimizar o impacto desses desafios na formação continuada.

Com base nos resultados da formação continuada e nas análises dos formadores, a proposta de formação de professores será revista, com perspectivas de avançar para um modelo on-line, com encontros síncronos e assíncronos, além de migrar para uma organização com base no desenvolvimento de competências docentes tendo como base o currículo tecnologia e computação do CIEB e as Competências Docentes de Pensamento Computacional da Sociedade Internacional de Tecnologia na Educação (ISTE).

Essas mudanças mostraram-se necessárias porque a proposta de formação continuada presencial, embora seja interessante para experiências práticas colaborativas, não favorece a capilarização da proposta, assim como evidenciam uma evolução no modelo de formação continuada do curso, tendo sido uma das sugestões dos professores.

A formação continuada revelou que os professores sentem necessidade e estão motivados a aplicar e desenvolver projetos integrando o Pensamento Computacional em suas práticas de ensino, porém precisam de apoio em suas unidades de ensino. Certamente, o que ainda precisa avançar também é a organização do processo e da gestão dos projetos nas escolas, visto que muitos professores revelaram que muitas ações não se concretizam no "chão da escola" por falta de acompanhamento e gerenciamento da equipe gestora.

Isto indica a necessidade de se oferecer também formação continuada para coordenadores pedagógicos e gestores no sentido de organizar projetos pedagógicos e espaços incluindo temas como o Pensamento Computacional, aprendizagem criativa e cultura maker nas escolas.

\section{REFERÊNCIAS}

[1] Avila, C., Bordini, A., Marques, M., Cavalheiro, S. e Foss, L.: Desdobramentos do Pensamento Computacional no Brasil. Anais do Simpósio Brasileiro de Informática na Educação (SBIE-2016), p.200-209, 2016.

[2] CIEB: Currículo de Referência em Tecnologia e Computação. Centro de Inovação para a Educação Brasileira, 2018. Disponível em: http://curriculo.cieb.net.br/.

[3] MEC: Base Nacional Comum Curricular. Ministério da Educação, 2018. Disponível em: http://basenacionalcomum.mec.gov.br/.

[4] Wing, J.: Computational Thinking. Communications of the ACM, 49(3), 2006

[5] Valente, J. A. Integração do pensamento computacional no currículo da educação básica: diferentes estratégias usadas e questões de formação de professores e avaliação do aluno. Revista E-curriculum, 14(3), 864-897, 2016.

[6] Mandaji, M., Da Silva, R. K., Terçariol, A. A. D. L., \& Mazurkievicz, G. L. (2018). O Programaê! e a formação de professores para a integração do pensamento computacional ao Currículo. CIET: EnPED.

[7] Papert, S. (1994). A máquina das crianças. Porto Alegre: Artmed, 17.

[8] Zanetti, H., \& Oliveira, C. (2015, October). Práticas de ensino de Programação de Computadores com Robótica Pedagógica e aplicação de Pensamento Computacional. In Anais dos Workshops do Congresso Brasileiro de Informática na Educação (Vol. 4, No. 1, p. 1236).

[9] De Paula, B. H., Valente, J. A., \& Burn, A. (2014). O uso de jogos digitais para o desenvolvimento do currículo para a Educação Computacional na Inglaterra. Currículo sem Fronteiras, 14(3), 46-71.

[10] Brennan, K., \& Resnick, M. (2012, April). New frameworks for studying and assessing the development of computational thinking. In Proceedings of the 2012 annual meeting of the American educational research association, Vancouver, Canada (Vol. 1, p. 25).

[11] Silva, V., da Silva, L. L., \& França, R. (2017, October). Pensamento computacional na formação de professores: experiências e desafios encontrados no ensino da computação em escolas públicas. In Anais do Workshop de Informática na Escola (Vol. 23, No. 1, p. 805).

[12] Barcelos, T., Bortoletto, R., \& Andrioli, M. (2016, November). Formação online para o desenvolvimento do Pensamento Computacional em professores de Matemática. In Anais dos Workshops do Congresso Brasileiro de Informática na Educação (Vol. 5, No. 1, p. 1228).

[13] Ramalho, B. L. (2013). Formação, representações e saberes docentes: elementos para se pensar a profissionalização dos professores. Mercado de letras.

[14] Grover, S., \& Pea, R. (2013). Pensamento computacional em K-12: Uma revisão do estado do campo. Pesquisador educacional, 42(1), 38-43.

[15] Almeida, M. D., \& Valente, J. A. (2011). Tecnologias e currículo: trajetórias convergentes ou divergentes. São Paulo: Paulus, 1, 93.

[16] Raabe, A. L. A., Gomes, A. S., Bittencourt, I. I., \& Pontual, T. (2016). Educação criativa: multiplicando experiências para a aprendizagem. Pipa Comunicação.

[17] Lévy, P. (2007). Inteligência coletiva (A). Edições Loyola. 